\title{
Hydronephrosis In Children and Kidney Dynamic Scintigraphy
}

\section{Luljeta Abdullahu MD"1*, Violeta Grajqevci MD PhD ${ }^{2 *}$, Naser Gjonbalaj MD PhD ${ }^{3}$, Fitore Murati-Abdullahu' ${ }^{4}$, Vjollca Dedushaj-Fazliu Mr Sci ${ }^{5}$ and Mimoza Berbatovci Ukimeraj MD PhD6}

${ }^{1}$ Department of Nuclear Medicine, University Clinical Center of Kosova, Republic of Kosovo

${ }^{2}$ Clinic of Pediatric-Hemato-oncology Department, University Clinical Center of Kosova, Republic of Kosovo

${ }^{3}$ Clinic of Radiology, University Clinical Center of Kosova, Kosova

${ }^{4}$ Department of Physiotherapeutic, University Clinical Center of Kosova, Republic of

Kosovo

${ }^{5}$ Clinic of Endocrinology, University Clinical Center of Kosova, Republic of Kosovo

${ }^{6}$ Clinic of Nephrology, University Clinical Center of Kosova, Republic of Kosovo

*Corresponding Author: Luljeta Abdullahu, Department of Nuclear Medicine, University

Clinical Center of Kosova, Republic of Kosovo. E-mail: luljeta.ab@gmail.com and Violeta

Grajçevci MD PhD, Clinic of Pediatric-Hemato-oncology Department, University Clinical

Center of Kosova, Republic of Kosovo. E-mail: violetagrajqevci@hotmail.com
Received: June 25, 2020

Published: November 17, 2021

(C) All rights are reserved by Luljeta

Abdullahu., et al.

\section{Abstract}

The Goal: Qunatification and classification of Hydronephrosis in children with Nuclear Medicine diagnostic method.

Methods: Retrospective study that has involved 49 pediatric patients in the time period from January to October 2015 at the age group from 2003 to 2015 (with an average age of 4.0 years). Dynamic study of the kidney is made with the protocol predefined study duration of 20 min.for time of $99 \mathrm{~m}$ Tc-DTPA administration-that.The images were taken with two detectors gamma camera with a low energy collimators and high resolution power in the rear projection.

Results: Of 49 patients to examine the dynamic kidney scintigraphy, 34 (69\%) showed signs of morphological (anatomical) and functional hydronephrosis in varying degrees of development caused by different causes.The study included 19 (40\%) cases of female with an average age of 4.68 years, and 30 cases were male (60\%) with an average age of 3.86 years. Hydronephrosis of 34 cases with 14 females (41.17\%) and 20 males (58.82\%).

Conclusion: The method provides accurate high-quality diagnostic determination of the case of hydronephrosis, together with the test with "forced" diuresis predicts the nature of significant impairments in function and helps in the early detection of deterioration of functional mass.

Keywords: Hydronephrosa; Dynamic Renal Scan; 99m Tc-DTPA; Test with “Forced” Furosemide Diuresis; Ecam-gamma Camera

\section{Introduction}

Hydronephrosa is referred to as enlargement of the pelvis and kidney cavity, it is not synonymous with obstructions.

Obstructions (obstructions) are clinically defined as resistance to urine flow [1].
Obstructions in every segment of the trunk cause dilation of the pielokalic system as well:

- Obstructive-uropathy is a change in the output tract due to an obstructive process (Hydonephrose, hydrourether) which, if not treated, leads to renal impairment 
- $\quad$ Obstructive -Nephropathy- is the effect of a kidney function blocking process.

Incidence

- Renal hydronephrosis was used as criteria with pelvis diameter $>5 \mathrm{~mm}$.

- It is considered a clinically significant incidence of about 1 : 600 hydronephrosis babies.

- The incidence of UPJO in pediatrics is about

- $\quad 60-70 \%$ of all causes of the dilated system

They may be

- Unilateral, commonly encountered in ureter, P-U strain and/ or renal pelvis

- $\quad$ Bilateral, caused by obstructions at the bladder or urethra [2].

Etiology

- $\quad$ Anatomic

- Functional (10-15\% of babies have a physiological hydronephrosis

- $\quad$ Neurological (neurological bladder).

Excluding children with temporary and physiological hydronephrosis, narrow stenosis Ureteropelvic and VUR remain the most common causes of clinically important tubular expansion.

Imaging method - Dynamic kidney scintigraphy

Dynamic radionuclide kidney scintigraphy, in particular diuretic scintigraphy, provides reliable data on functional parameters with

- The GFR glomerural filtration rate assessment,

- $\quad$ Relative differential kidney function, and with drainage pattern (determines the degree of hydronephrosis of functional importance).

International Consensus Committee Recommendations for Basic Renogram [3].
Radiopharmaceutical

- 99mTc-DTPA, (Diethylene-triamino-pentaacid)

- After application i.v minimally binds to plasma proteins about 2-6\%,

- Only secreted with glomerular filtration

- With a further passage through the tubular system it is neither resorbed nor secreted into the tubular cells.

Excretion mechanisms

$\begin{array}{llll}\text { G } & \text { GF } & \text { TS } & \text { TF }\end{array}$

$$
\text { Tc-99m DTPA } \quad>95 \%
$$

$\begin{array}{ccc}\text { Extract. fraction } & \text { Clearance } \\ \times \text { Tc-99m DTPA } & 20 \% & 100-120 \mathrm{ml} / \mathrm{min}\end{array}$

Int'l Consens. Comm.Semin NM '99:146-159(3)

\section{Methods}

Patient preparation

- Appropriate solubility with physiological digestion or water

- Give $10-15 \mathrm{ml} / \mathrm{kg}$ of water or physiological digestion, depending on the age of the child 30-60 min. pre-injection

- To empty the bladder prior to the study, and at the end of the study if indicated diureses $[3,17]$.

Aquisition

- $\quad$ Preferably the patient's extended position (supine)

- Camera-larg FOV dhe

- Colimator LEHR

- In the rear projection

Dynamic kidney scintigraphy was performed during 20 minutes

- $\quad$ Flow (angiogram) $2 \mathrm{sec} /$ frem per 30 freme (1 min)

- Dynamic: $20 \mathrm{sec} /$ frame x 20min (60 freme), matrix 64x64

Static study, sequencing obtained for $6 \mathrm{~min}$ )(display - $6 \mathrm{~min} /$ 
frame) matrixa $128 \times 128$ acording to International Consensus Committee Recommendations for Basic Renogram [3],

- $\quad$ After injection i.v. 99mTc-DTPA

- $\quad$ Using a dose of $50 \mu \mathrm{Ci}(1.85 \mathrm{MBq} / \mathrm{kg})$, min dose of $20 \mathrm{MBq}$ ), preferred by the EANM pediatric dosage calculator started with $[4,18]$.

With the gamma cameras, simultaneously on screen, to monitor the arrival of kidney-related radiopharmaceutical preparations (excretion) and elimination from the kidneys we serve with the renography curve and scintigraphy (photographs).Observed sequences of dynamic frames and renographic curvature during acquisitionis.

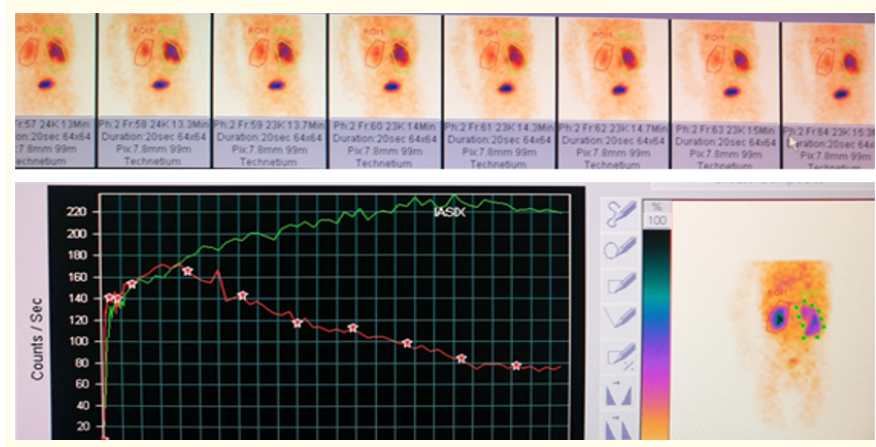

Diagram 1: If the study requires diuretic administration -applicate $0.5-1 \mathrm{mg} / \mathrm{kg}$ (maximum dose $20 \mathrm{mg}$ ) furosemide in the $15^{\text {th }}$ minute of study after injecting the radiopharmaceutical or after $20 \mathrm{~min}$ to continue for $15 \mathrm{~min}(\mathrm{~F}+20)[5,6,19]$.

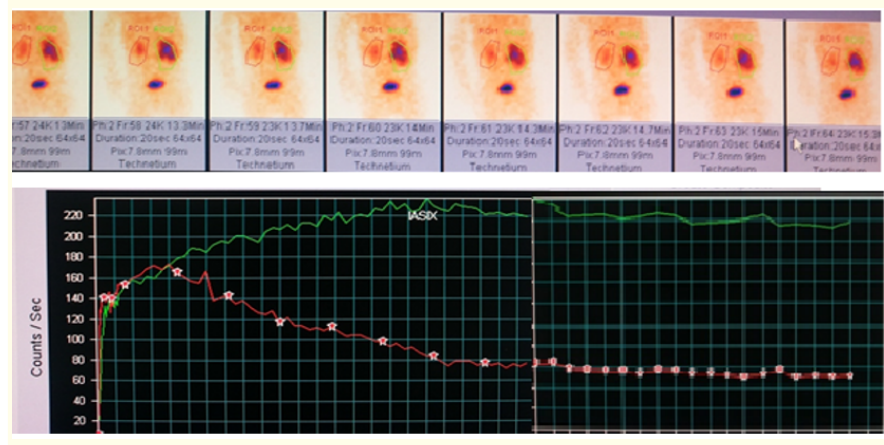

Diagram 2: After 20 minutes to continue for 15-20 min. $(F+20)$.

\section{Processing}

Qualitative analysis consists in evaluating the function based on the analysis of photographs of the entire study(sequential scintigraphy).

From the sum of standard scintigraphy, the parenchymal phase (2-3 $\mathrm{min})$ is estimated:

- $\quad$ Size and kidney shape

- $\quad$ The homogeneity and intensity of the parenchy presented and

- The function evaluation in relation to the intensity of background

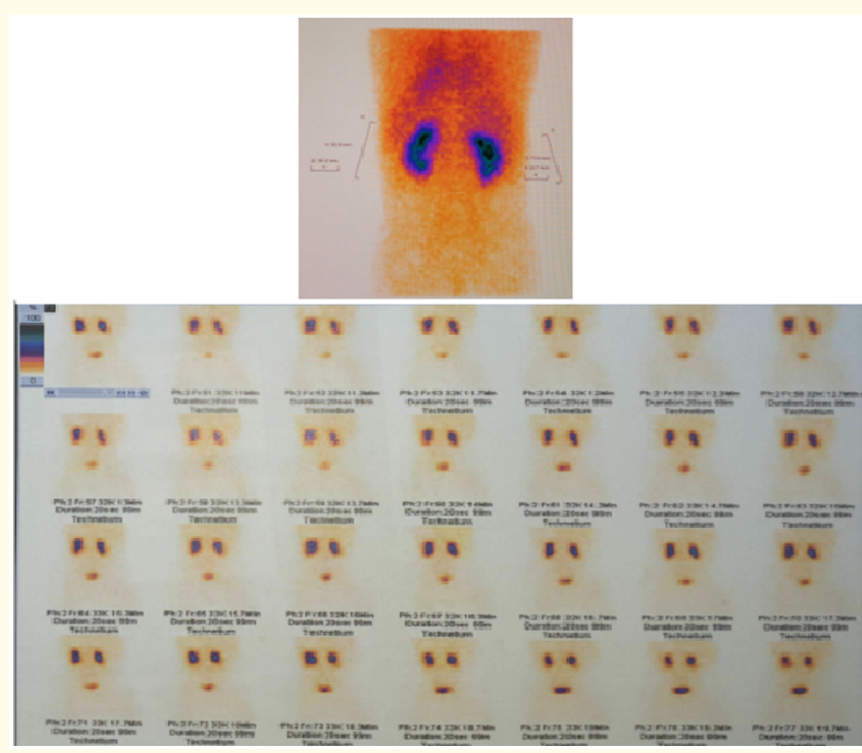

Diagram 3: From the sequences (the following scintigraphs) is estimated: the further kinetics of the radio-pharmaceutical reparation, - its removal from the kidney and possibly the residual activity recorded in the system of the assigned part - pielokaliceal and - the activity in the bladder is also evaluated.

Quantitative analysis-The important parameters in the evaluation of renal function are obtained:

- Relative values of the differential function in the interval of 2-3 minutes calculated with the intergral method and 
- Glomerular Filtration Rate (GFR), 160 L/day (male 125 +/- 26

$\mathrm{ml} / \mathrm{min}$, female $110+/-14 \mathrm{ml} / \mathrm{min}$ )

The quantitative analysis consists in determining the kidney region (ROI) region as in the following figure, and generating the renographic curve.

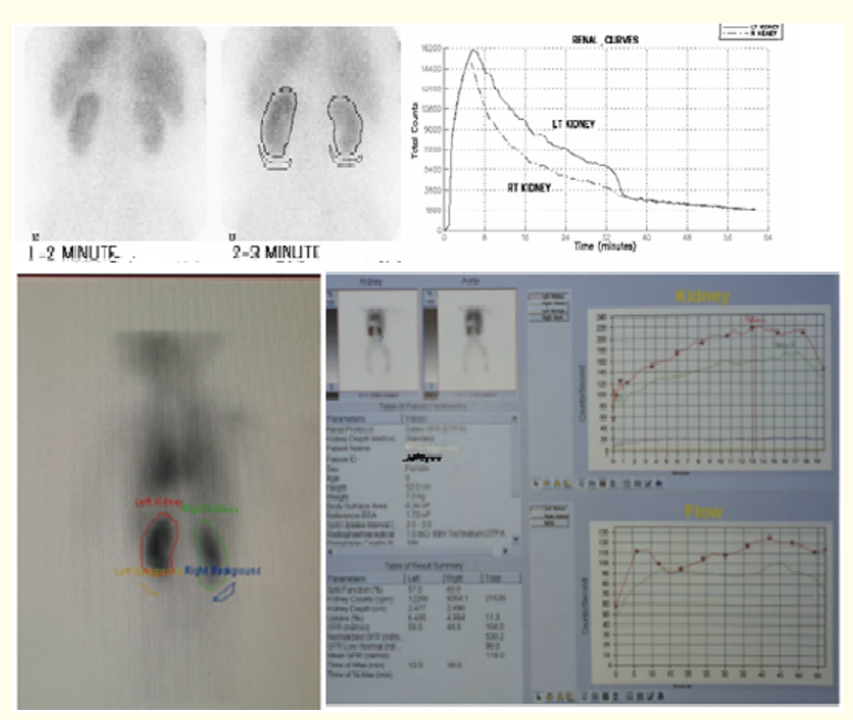

Diagram 4: Relative (split) function-ROI's [7,8].

Differential kidney function behaves

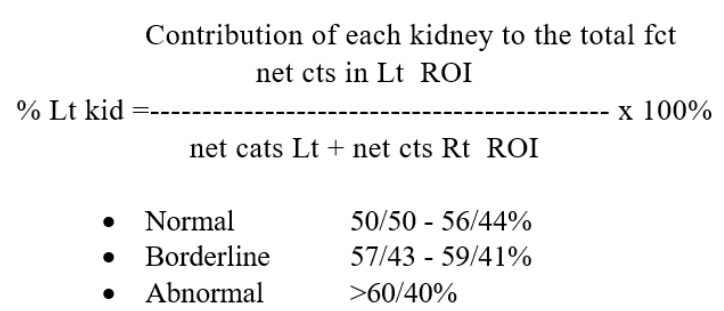

Classification of Hydronephrosis

Can be quantified"washout" $\left(\mathrm{T}_{1 / 2}\right)$

Test with "forced" diuresis

Without the UPJ (Pyelo-urethral junction) obstruction, "positive"

- Hydronephrosis of mild degree $\operatorname{Tmax}_{1 / 2}=>10-15 \mathrm{~min}$

- Hydronephrosis moderate (Intermediate) $\mathrm{T}_{1 / 2}=15-20 \mathrm{~min}$.

UPJ (Pyelo-urethral junction) obstruction, "negative".
Pre-Lasix

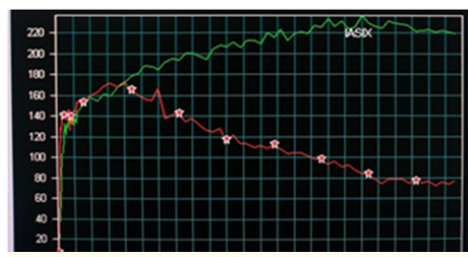

Diagram 5: Pyelo-urethral junction obstruction negative [9-12].

\section{Results}

Significant Obstructions in:

- $\quad 34 / 49$ children (69\%) showed urinary tract obstruction,

- With lightweight hydronephrosis with $\mathrm{T}_{1 / 2}=>10-15 \mathrm{~min}$. to $4 / 34$ (11.76\%) or $8.16 \%$ from 49 patients,

- Intermediate scale with $\mathrm{T}_{1 / 2}=15-20 \mathrm{~min}$. at $20 / 34$ (58.82\%), or $40.81 \%$ out of 49 children and

- $\quad$ Severe scale of urinary tract obstruction with $\mathrm{T}_{1 / 2}=>20$ min. at $10 / 34(30 \%)(20.4 \% / 49)$, a diuretic test has been done

- In $3 / 10(30 \%)$, or $6.12 \% / 49$ children responded negatively- (complete obstruction was detected in three patients)

- In $7 / 10(70 \%)$, or $14.28 \% / 49$, the response was positive - without obstruction.

- $\quad$ Cause of cervical pyelourethralis stenosis were 14 cases (41.17\%), with juxtavesicale stenosis 3 cases (8.82\%),

- $\quad$ Hydronephrosis with megaureter in 11 cases (32.35\%),

- hydronephrosis associated with IUT, and reflux 6 cases (17.64\%).

- $\quad$ Based on the sequence of dynamic images and renographic curve depending of $\mathrm{T} 1 / 2$ (the time required to release $50 \%$ of units tracer of the dilated kidney), they are classified into Hydronephros degrees: 
- $\quad$ Light, Intermediate and grave, without obstructing the $\mathrm{T} 1 / 2$ $10-20 \mathrm{~min}$ in 24 cases (70\%) and $\mathrm{T} 1 / 2>20 \mathrm{~min}$ in 10 cases (30\%), of which $5(14.70 \%)$ cases with signs obstructive, even after the test to verify the forced diuresis.

- $\quad$ Based on the measurement of GFR, two patients showed worsening hydronephrosis with $\mathrm{GFR}=<50 \mathrm{ml} / \mathrm{min}$.

The results of GFR

- In $3 / 49(6.1 \%)$ children showed a reduced function with GFR $<50 \mathrm{ml} / \mathrm{min}$, (55.55\%, less)

- In $6 / 49(12.24 \%) \mathrm{GFR}=75-80 \mathrm{ml} / \mathrm{min}$ lightly reduced function, $12 \%$ less than the lower limit values)

- In $9 / 49(18.26 \%)$ with $\mathrm{GFR}=80-90$-lower border

- In $31 / 49(63.26 \%)$ with no GFR reduction and DRF (differential renal function) $52.4 \% / 47.6 \%$, about $10 \%$ less.

\begin{tabular}{|c|c|c|c|c|}
\hline Sex & $\begin{array}{c}\text { N/\% of, } \\
\text { patients }\end{array}$ & $\begin{array}{c}\text { The } \\
\text { average age }\end{array}$ & Hydronefrosis & \% \\
\hline Total & 49 & 4.9 & 34 & 69 \\
\hline Girls & $19(40 \%)$ & 4.48 & 14 & 41.17 \\
\hline Boys & $30(60 \%)$ & 3.86 & 20 & 58.82 \\
\hline
\end{tabular}

Table 1: Classification by sex and age.

\begin{tabular}{|c|c|c|c|c|}
\hline $\begin{array}{c}\text { Hydronephrosis/ } \\
\text { cause }\end{array}$ & $\mathbf{N}$ & $\mathbf{\%}$ & Girls & Boys \\
\hline $\begin{array}{c}\text { UPJO (Pyelo-urethral } \\
\text { junction obstruction) }\end{array}$ & 14 & 41.17 & $5(4.70 \%)$ & $9(26.47 \%)$ \\
\hline $\begin{array}{c}\text { UVJO(Stenosis. } \\
\text { Uretrovesical) }\end{array}$ & 3 & 8.82 & $1(2.94 \%)$ & $2(5.84) \%$ \\
\hline Megaurether & 6 & 17.64 & $1(2.94 \%)$ & $5(14.70 \%)$ \\
\hline $\begin{array}{c}\text { urinary tract } \\
\text { insufficiency }\end{array}$ & 6 & 17.64 & $3(8.82 \%)$ & $3(8.82 \%)$ \\
\hline others & 5 & 14.70 & $2(5.84 \%)$ & $3(8.82 \%)$ \\
\hline
\end{tabular}

Table 2: Evaluation by cause and segment level (obstruction) presented.

\begin{tabular}{|c|c|c|c|}
\hline Hydronef & $\mathbf{T 1 / 2}$ & $\mathbf{N = 3 4}$ & $\mathbf{\%}$ \\
\hline Low & $>10-15 \mathrm{~min}$ & 4 & $11.76 \%$ \\
\hline Intermediate & $15-20 \mathrm{~min}$ & 20 & $58.82 \%$ \\
\hline Severe & $>20 \mathrm{~min}$ & 10 & $30 \%$ \\
\hline
\end{tabular}

Table 3: Evaluation according to the degree of obstruction presented.

\begin{tabular}{|c|c|c|c|}
\hline Side & N & Girls & Boys \\
\hline Hydr.unilat & $25(73.5 \%)$ & $8(32 \%)$ & $17(68 \%)$ \\
\hline Hydr.Bill. & $9(26.47 \%)$ & $4(44.44 \%)$ & $5(55.55 \%)$ \\
\hline Left kidney & $10(29.4 \%)$ & $3(15.78 \%)$ & $7(23.33 \%)$ \\
\hline Right kidney & $15(44.11 \%)$ & $5((33.33 \%)$ & $10((66.66 \%)$ \\
\hline
\end{tabular}

Table 4: Evaluation by Side.

\begin{tabular}{|c|c|c|c|}
\hline $\begin{array}{c}\text { Basic study, } \\
\text { with Hydr. }\end{array}$ & $\begin{array}{c}\text { Without } \\
\text { obstr. } \\
\mathbf{2 4}(\mathbf{7 0 \% )}\end{array}$ & $\begin{array}{c}\text { With obstr. } \\
\mathbf{1 0} \mathbf{( 3 0 \% )}\end{array}$ & $\begin{array}{c}\text { Forciss diuressis, } \\
\text { 3 patient with } \\
\text { obstr. }\end{array}$ \\
\hline Ren dex 10 & 7 & 3 & 1 \\
\hline Ren sin 15 & 9 & 6 & 2 \\
\hline Bill. 9 & 8 & 1 & 0 \\
\hline
\end{tabular}

Table 5: Evaluation from the aspect of obstruction before and after Lasix.

\begin{tabular}{|c|c|c|c|}
\hline GFR & $\mathbf{m l} / \mathbf{m i n}$ & $\mathbf{N}=\mathbf{4 9}$ & $\mathbf{\%}$ \\
\hline Reduced & $<50$ & 3 & 6.1 \\
\hline Lightly & $75-80$ & 6 & 12.24 \\
\hline Borderline & $80-90$ & 9 & 18.26 \\
\hline Normal & $>90$ & 31 & 63.26 \\
\hline
\end{tabular}

Table 6: Evaluation from the aspect of GFR.

Evaluation of Hydronephroses/Indications

- Evaluation of Functional Importance of Hydronphrosis

- Defines the need for surgical treatment of obstructive hydronephrosis, and

- Medication therapy of hydronphrosis without obstruction 
- Monitoring the Effect of Therapy

Clinical indications for diuretic renography are

- $\quad$ Suspected obstructive nephropathy or uropathic obstructions associated with hydronephros or kidney stones, malignant disease or retroperitoneal fibrosis, etc.

- In children, when vesicoureteral or pelvic-ureteral stenosis is suspected as a common indicator.

Possible Mistakes in Diuretic kidney Scintigraphy

- False positive for obstruction

- $\quad$ Bladder relaxed/distended (Puffy)

- Gross hydronephrosis

$\mathrm{T}($ transit time $)=\mathrm{V}$ (volume $) \div \mathrm{F}($ flow $)$

- $\quad$ Poor and/or immature kidney function

- Dehydration

- $\quad$ False negative

- Low degree of obstruction

- $\quad$ Poor functioning/immature kidneys

\section{Discussion}

- Our studies are consistent with the authors' findings in their publications [13] (Our study confirmed the findings of Dudley., et al.) that, Stenoses in the urinary tract, still leading to $>60 \%$ of Hydronephrous, followed by VUR (vesico urethrewl reflux) [14] 10 found VUR in 17\%, as a frequent companion to these findings.

- $\quad$ Our contribution to these cases in our unit consists of providing highly probable information services and information about the functional state of the kidneys with apparent or unpredictable constraints but which are potentials for impairment of the functional kidney mass and to limit the number of kidneys patients with severe consequences - unacceptable.
- Our studies are compatible and are not limited by other published studies.

- The timely detection of prenatal Ultarsonography hydronephrosis (timely detection of ITU, VUR and other congenital abnormalities, along with radionuclide methods, are indiscriminate studies in evaluating functional kidney status in infants and children [15,16,20].

\section{Conclusion}

- UPJO (Pyelo-urethral junction obstruction) as frequent causes of hydronphage detected during prenatal and postnatal evaluation, and our results showed that renal diuretic scintigraphy is a predictive and determinant method in detecting the presence and significant obstructions.

- Over $60 \%$ of findings with obstructions and over $30 \%$ of other abnormal findings confirm that dynamic 99mTc-DTPA scintigraphy can be used not only in early diagnostic on obstructions of functional importance, but also in therapeutic evaluation.

\section{Bibliography}

1. Cortes D., et al. "[Prenatal diagnosed hydronephrosis and other urological anomalies]”. Ugeskr Laeger 168 (2006): 2544-2550.

2. Homsy YL., et al. "Transitional hydronephrosis of the newborn and infant". The Journal of Urology 144 (1990): 579-583.

3. Int'l Consens. Comm.Semin NM '99:146-159 International Consensus Committee Recommendations for Basic Renogram Taylor, Semin NM 9 146-159.

4. Piepsz A and Ham HR. "Pediatric applications of renal nuclear medicine". Seminars in Nuclear Medicine 36.1 (2006): 16-35.

5. Sampson C. "Textbook of Radiopharmacy". $3^{\text {rd }}$ edition. Amsterdam: Gordon and Breach (1999).

6. Kao PF., et al. "The 99mTc DMSA renal scan and 99mTc-DTPA diuretic renogram in children and adolescents with incidental diagnosis of horseshoe kidney". Nuclear Medicine 24 (2003): 525-530.

7. Steiner D., et al. "The value of renal scintigraphy during controlled diuresis in children with hydronephrosis". European Journal of Nuclear Medicine and Molecular Imaging 26 (1999): 18-21. 
8. British Society of Nuclear Medicine. Dynamic Renal Radionuclide Studies (2003).

9. O'Reilly P., et al. "Consensus on diuresis renography for investigating the dilated upper urinary tract. Radionuclides in Nephrourology Group. Consensus committee on Diuresis Renography". The Journal of Nuclear Medicine 37 (1996): 18721876.

10. Rao S. “Obstructive Uropathy, Acute (2009).

11. Koff SA. "Requirements for accurately diagnosing chronic partial upper urinary tract obstruction in children with hydronephrosis". Pediatric Radiology 38.1 (2008): 41-48.

12. Br JUrol 1987:10-14 Upsdell, Br JUrol (1992): 126-132.

13. Dudley JA., et al. "Clinical relevance and implications of antenatal hydronephrosis". Archives of Disease in Childhood: Fetal and Neonatal Edition 76 (1997): F31-34.

14. Arena S., et al. "A long-term follow-up in conservative management of unilateral ureteropelvic junction obstruction with poor drainage and good renal function". European Journal of Pediatrics 177 (2018): 1761-1765.

15. Yiee J and Wilcox D. "Management of fetal hydronephrosis". Pediatric Nephrology 23 (2008): 347-353.

16. Karnak I., et al. "Prenatally detected ureteropelvic junction obstruction: clinical features and associated urologic abnormalities". Pediatric Surgery International 24 (2008): 395-402.

17. Gordon I., et al. "Pelvis retentive junction obstruction: The value of post micturition view in Tc99m DTPA diuretic demography". Brazilian Journal of Urology 61 (1988): 409-412.

18. Toiviainen-Salo S., et al. "Fetal hydronephrosis: is there a hope for consensus?" Pediatric Radiology 34.4 (2004): 519-529.

19. Gordon I. "Pathophysiology of renal function and its effect on isotope studies in the workup of hydronephrosis". World Journal of Urology 22 (2004): 411-414.

20. Blaufox MD., et al. "Report of the Radionuclides in Nephrourology Committee on renal clearance". The Journal of Nuclear Medicine 37 (1996): 1883-1890.

Volume 5 Issue 12 December 2021 (C) All rights are reserved by Luljeta Abdullahu., et al. 